\title{
Susceptibility to smoking and determinants among medical students: A representative nationwide study in China
}

\author{
Sihui Peng ${ }^{1+}$, Lingwei $\mathrm{u}^{1+}$, Tingzhong Yang ${ }^{2 *}$, Dan Wu ${ }^{3}$, Joan L. Bottorff, Ross Barnett ${ }^{5}$, Shuhan Jiang ${ }^{6 *}$
}

\begin{abstract}
INTRODUCTION The rationale behind why the majority of medical students are non-smokers, but some initiate smoking after becoming physicians is not fully understood in China. Exploring factors that may increase susceptibility to smoking initiation among medical students is an essential first step in assessing preventative actions.

METHODS Participants were 11954 students, who were identified through a multistage survey sampling process that included 50 universities in China. Subsequent analysis focused on 8916 non-smokers among medical students. Both unadjusted and adjusted logistic methods were considered in the data analyses.

RESULTS The prevalence of susceptibility to smoking was 23.0\%. Multivariate logistic regression analyses found that exposure to secondhand smoke (SHS) in domestic places $(\mathrm{OR}=1.63)$ and in public places $(\mathrm{OR}=1.78)$, cigarette advertising $(\mathrm{OR}=1.91)$ and promotional activities on campus $(\mathrm{OR}=1.90)$ were positively associated with susceptibility to smoking. In contrast, positive attitudes toward tobacco control on the part of health professionals, HPs, $(\mathrm{OR}=0.52)$ were negatively associated with susceptibility to smoking. Those who received information about the dangers of smoking $(\mathrm{OR}=0.75)$ and did not agree that light cigarettes are less harmful to health $(\mathrm{OR}=0.79)$ were less susceptible to smoke. Caring about exposure to secondhand smoke ( $\mathrm{OR}=0.68$ care, and $\mathrm{OR}=0.33$ very) and advising family members to stop smoking $(\mathrm{OR}=0.81)$ were negatively associated with susceptibility to smoking.

CONCLUSIONS These findings underscore the importance of tobacco control training and establishing smoke-free campuses for reducing susceptibility to smoking among medical students.
\end{abstract}

\author{
AFFILIATION \\ 1 Center for Tobacco Control Research, \\ Zhejiang University School of Medicine, \\ Hangzhou, China \\ 2 Children's Hospital/Center for Tobacco \\ Control Research, Zhejiang University \\ School of Medicine, Hangzhou, China \\ 3 Department of Psychology, Guangdong \\ Medical University, Dongguan, China \\ 4 School of Nursing, University of British \\ Columbia, Kelowna, Canada \\ 5 Department of Geography, University \\ of Canterbury, Christchurch, New \\ Zealand \\ 6 School of Humanities and \\ Management, Zhejiang Chinese Medical \\ University, Hangzhou, China \\ + Co-first authors \\ \#Co-correspondence authors \\ CORRESPONDENCE TO \\ Tingzhong Yang. Children's Hospital/ \\ Center for Tobacco Control Research, \\ Zhejiang University School of Medicine, \\ Hangzhou 310052, China. \\ E-mail: Tingzhongyang@zju.edu.cn \\ Shuhan Jiang. School of Humanities and \\ Management, Zhejiang Chinese Medical \\ University, Hangzhou 310053, China. \\ E-mail: shuhan_jiang@163.com \\ KEYWORDS \\ susceptibility to smoking, tobacco \\ control, college students, China
}

Received: 14 January 2019 Revised: 28 February 2019

Accepted: 5 April 2019

\section{INTRODUCTION}

Smoking is a behavioral change that may occur gradually through several stages of preparation, initiation, experimentation, regular smoking, and addiction $^{1,2}$. Susceptible non-smokers are defined as people who are currently not smoking, but who are predisposed or motivated to start smoking in the future. Thus, susceptibility to smoking is defined as the absence of a firm decision not to smoke. Likewise, non-susceptibility is defined as the existence of a determined decision not to smoke $^{3,4}$. Many studies have found that an early 
susceptibility to smoking is a strong predictor of smoking initiation ${ }^{3,5,6}$ but there has been some debate regarding the extent to which susceptibility is a direct predictor of smoking initiation ${ }^{7}$. Researchers have also found that susceptibility to smoking increases participation in tobacco industry promotion campaigns ${ }^{8,9}$, as well as decreased responsiveness and compliance with tobacco prevention programs ${ }^{2,10}$.

While such studies have proved valuable in conceptualizing the factors that lead to smoking initiation among youth, there are a number of critiques that can be made. First, while there are many studies that have explored adolescent susceptibility to smoking, these have mostly been confined to high-income countries ${ }^{8}$, and few studies have examined susceptibility in low- and middle-income countries ${ }^{1,11}$. Second, most of the studies have examined adolescents, and only a few have focused upon young adults and college students ${ }^{12,13}$. To the best of our knowledge, none has focused on medical students. Third, most research has focused on individual-level factors, yet ecological models emphasizing behavioural events are influenced by both individual and environmental variables ${ }^{14}$. Thus, it is important also to consider the latter and the way environmental factors may influence susceptibility ${ }^{15}$. For example, a number of studies have found that susceptibility to smoking reflects the intensity of tobacco industry promotion campaigns ${ }^{8,9,16}$, while other studies have shown clear associations between weak smoke-free policies, exposure to secondhand smoke (SHS) and susceptibility to smoking ${ }^{2,12}$.

Smoking prevalence remains high in China and medical college students, as future health professionals (HPs), are important agents for tobacco control. Health professionals play a critical role in improving services, advocating policies and serving as role models for social change. However, the smoking prevalence among physicians is much higher (23\%) in China, especially among males ${ }^{16}(41 \%)$, compared to many other countries, particularly developed countries (about $6 \%)^{17,18}$. Compared with the smoking prevalence $(33 \%)$ of the general population, the physician smoking ratio is $0.70(23 / 33)$ in China, while this ratio is only $0.30(6 / 20)$ in the western world ${ }^{17}$. This is a matter of concern because physician smoking not only affects their own health but also undermines the effective delivery of smoking cessation counselling to patients ${ }^{18-20}$. Jiang et al. ${ }^{17}$ in their study of 3552 hospital-based physicians in six Chinese cities reported that only 30\% HPs reported good implementation of smoke-free workplace policies and $37 \%$ (of current smokers) had smoked in front of their patients ${ }^{16}$. Such trends are reminiscent of HPs in western countries such as the United States where cigarette smoking prevalence among physicians in $1974(18.8 \%)$ was similar to that of China's HPs 30 years later ${ }^{21}$.

Some medical students who are non-smokers begin to smoke after becoming physicians but the reasons for this are not fully understood. Some studies have suggested that social factors are important, such as the lack of anti-smoking norms, work stress, or physicians accepting cigarettes as gifts from patients ${ }^{16,22}$. Some physicians begin smoking as their attitudes, and practices of smoking start to reflect their experiences, and changes in their health behavior gradually begin to occur ${ }^{14}$. Exploring factors that may increase susceptibility to smoking initiation among medical students therefore is an important step in developing prevention strategies to reduce smoking rates among future physicians.

Most medical students in China eventually work in the healthcare industry including public hospitals (majority of Chinese hospitals), private clinics, and other healthcare units after graduation, as undergraduate, Masters or Doctoral students ${ }^{23}$, and nearly all of them work as physicians in these institutes ${ }^{24}$. Susceptibility to smoking as medical students may be a risk factor for the physicians' actual smoking behaviours ${ }^{3,5,6}$, so that examining the susceptibility to smoking of medical students is important to understanding physicians' smoking behaviour.

This study, therefore, focuses on examining susceptibility to smoking and its determinants among medical students by assessing three questions: 1) What is the prevalence of susceptibility to smoking among medical students who have never smoked?; 2) What environmental factors influence medical students' susceptibility to smoke?; and 3) What kind of individual tobacco control attitudes, and university curriculum practices are associated with susceptibility to smoking? 


\section{METHODS}

\section{Study area and participants}

This study reports individual data from the Global Health Professions Student Survey (GHPSS) on Tobacco Control in China GHPSS ${ }^{11}$. This study employed a multi-stage sampling design. In Stage 1, 60 potential universities with medical programs were identified across regions in China. Fifty of the 60 universities actually completed the survey process. These universities were distributed throughout China (Northeast, Northwest, North, Southeast, Southwest and South). Twenty-two were medical universities offering mainly medical professional programs, and 28 were comprehensive universities offering medical professional and non-medical professional programs. Stage 2 of the sampling strategy involved the selection of levels within each university. All levels that had medical professional courses were selected in each university. In Stage 3, one-third of those classes were randomly selected from each level. In Stage 4, all students in these selected classes were surveyed. A detailed description of the study methods can be found in Yang et al. ${ }^{22}$.

\section{Data collection}

Data were collected using a self-report method. Once participants were identified and agreed to participate in the study, a structured self-administered questionnaire was used. The questionnaire was administered during regular class sessions and took approximately 30 minutes to complete. All responses were anonymous. A common research protocol was used across all 50 universities to ensure homogeneity of questionnaire administration and data collection techniques. A detailed description can be found in Yang et al. ${ }^{22}$. For the purpose of this study, only medical students who were never smokers were included in the analysis. Never-smoking medical students were identified as those participants who responded 'no' to smoking at present or in the past. This study was approved by the Ethics Committee at the Medical Center, Zhejiang University, and verbal consent was obtained from all participants prior to data collection.

\section{Measures}

Dependent variable

The dependent variable is susceptibility to smoking among never-smoking medical students and was obtained referencing three questions similar to those developed by Pierce et al. ${ }^{3}$. These considered social influences on smoking initiation in China ${ }^{14}$. The questions were: 1) 'Do you think that you will try a cigarette soon?'; 2) 'If some of your best friends smoke in the future, will you smoke?'; and 3) 'If social contact and work need you to smoke in the future, will you smoke?'. The following four-point ordinal scale was used: 1) definitely not, 2) probably not, $3)$ probably yes, and 4) definitely yes. Never-smoking medical students were identified as those participants who responded 'no' to smoking at present or in the past. Using previously described methods ${ }^{8}$, those who responded 'definitely not' to all three questions were considered as non-susceptible and recoded as ' 0 ', and all other respondents were considered susceptible to smoking and recoded as ' 1 '.

Cronbach's coefficient among three questions to measure susceptible to smoking was 0.7527 . The first question in our measure is the same as that of Pierce et al. ${ }^{2}$. Pearson correlation coefficients between the first question and the second, and third question within this sample were $0.68490(\mathrm{p}<0.0001)$ and 0.67067 $(p<0.0001)$. These findings support the validity of our measure.

\section{Independent variables}

Sociodemographic measures included age, sex, ethnicity, father's and mother's occupation, type of university, and monthly expenses. University type was determined using the China university ranking system ('Higher level,' 'Middle level,' or 'Lower level') as set out by the National Ministry of Education ${ }^{25}$. A monthly expense (RMB, China currency) was measured through a question: 'How much money do you spend each month?'.

Environmental factors were measured in two ways. The first was exposure to secondhand smoke (SHS) in private (domestic) and public places, while the second focused on cigarette advertisement and cigarette promotion activities. Students were asked whether they had been exposed to SHS in the past week either at home or in public places and whether they had seen cigarette promotional activities or advertisements on campus in the past six months (Table 1).

Students attitudes towards the role of health professionals in tobacco control were measured using six questions relating to whether physicians should obtain specific training on cessation techniques, serve as role models for their patients and the general 
Table 1. Sociodemographic characteristics of sample, the prevalence of susceptibility to smoking, and unadjusted odds ratio (OR)

\begin{tabular}{|c|c|c|c|c|}
\hline Group & $\mathbf{N}$ & $\begin{array}{l}\text { Per cent } \\
\text { of sample }\end{array}$ & $\begin{array}{c}\text { Prevalence } \\
\left({ }^{\circ}\right)\end{array}$ & $\begin{array}{l}\text { Unadjusted OR } \\
\qquad\left(95^{\circ} \circ \mathrm{CI}\right)\end{array}$ \\
\hline \multicolumn{5}{|l|}{ Sociodemographic variables } \\
\hline \multicolumn{5}{|l|}{ Age (years) } \\
\hline$<20$ & 1605 & 11.0 & 22.4 & 1.00 \\
\hline $20-$ & 1890 & 17.8 & 19.2 & $0.85(0.61-1.17)$ \\
\hline $21-$ & 2208 & 24.7 & 21.9 & $0.97(0.72-1.30)$ \\
\hline $22-$ & 2012 & 22.1 & 23.5 & $1.06(0.79-1.43)$ \\
\hline $23-$ & 2057 & 24.6 & 26.6 & $1.45(1.02-2.61)^{*}$ \\
\hline \multicolumn{5}{|l|}{ Gender } \\
\hline Male & 2959 & 31.0 & 41.9 & 1.00 \\
\hline Female & 6858 & 69.0 & 14.0 & $0.24(0.20-0.28)^{* *}$ \\
\hline \multicolumn{5}{|l|}{ Father's occupation } \\
\hline Worker, farmer, and business & 7790 & 79.2 & 23.6 & 1.00 \\
\hline Manager and staff & 1406 & 14.7 & 20.4 & $0.73(0.56-0.93)^{*}$ \\
\hline \multicolumn{5}{|l|}{ Teacher and science } \\
\hline and technical worker & 621 & 6.0 & 21.9 & $1.10(0.83-1.45)$ \\
\hline \multicolumn{5}{|l|}{ Mother's occupation } \\
\hline Worker, farmer, and business & 7910 & 80.1 & 23.4 & 1.00 \\
\hline Manager and staff & 1253 & 12.7 & 21.5 & $0.90(0.71-1.13)$ \\
\hline Teacher and science and technical worker & 654 & 6.8 & 21.4 & $0.89(0.68-1.17)$ \\
\hline \multicolumn{5}{|l|}{ Ethnicity } \\
\hline Han & 9214 & 95.3 & 23.1 & 1.00 \\
\hline Minority & 603 & 4.7 & 21.4 & $0.90(0.66-1.22)$ \\
\hline \multicolumn{5}{|l|}{ Monthly expenditure (RMB) } \\
\hline$<500$ & 1152 & 9.3 & 22.4 & 1.00 \\
\hline $500-999$ & 5152 & 54.2 & 22.7 & $1.02(0.70-1.48)$ \\
\hline $1000-1499$ & 2815 & 29.5 & 23.7 & $1.08(0.72-1.62)$ \\
\hline$\geq 1599$ & 718 & 6.9 & 23.4 & $1.06(0.68-1.67)$ \\
\hline \multicolumn{5}{|l|}{ University type } \\
\hline Higher level & 3597 & 43.1 & 21.0 & 1.00 \\
\hline Middle level & 5683 & 55.5 & 24.8 & $1.24(0.92-1.698)$ \\
\hline Lower level & 537 & 1.5 & 19.0 & $0.89(0.70-1.12)$ \\
\hline \multicolumn{5}{|l|}{ Exposure to SHS } \\
\hline \multicolumn{5}{|l|}{ Exposure in domestic places in past week } \\
\hline No & 7338 & 83.4 & 12.6 & 1.00 \\
\hline Yes & 1578 & 16.6 & 26.4 & $1.94(1.63-3.31)^{* *}$ \\
\hline \multicolumn{5}{|l|}{ Exposure in public places in past week } \\
\hline No & 4805 & 55.4 & 14.0 & 1.00 \\
\hline Yes & 4111 & 44.6 & 16.0 & $1.16(1.02-1.31)^{*}$ \\
\hline \multicolumn{5}{|l|}{ Cigarette advertisement and promotion } \\
\hline \multicolumn{5}{|c|}{ Did you see cigarette promotional activities on campus in the past 6 months? } \\
\hline No & 9212 & 95.1 & 22.3 & 1.00 \\
\hline Yes & 461 & 4.9 & 37.1 & $2.06(1.42-2.94)^{* *}$ \\
\hline
\end{tabular}


Table 1. Continued

Cigarette advertisement and promotion
Did you see cigarette advertisements on campus in past 6 months?

No

$\begin{array}{rr}9104 & 94.1 \\ 570 & 5.9\end{array}$

22.0

1.00

Attitude toward health professions (HPs) tobacco control

Should HPs obtain specific training on cessation techniques?

No

Yes

Should HPs serve as role models for their patients and the public?

No

Yes

Should HPs routinely advise patients to stop smoking?

No

Yes

Should HPs advise patients who use other tobacco products to quit using these products?

No

Yes

4455

54.4

45.6

Do HPs have role in providing advice or information about smoking cessation to patients?

No

1257

8560

12.3

87.7

1213

12.0

88.0

8604

Yes

Curriculum and practices

In school training, did you receive information about the dangers of smoking?

No

Yes

1802

17.1

27.5

1.00

8015

82.8

5412

Have you ever heard of nicotine replacement therapies in tobacco cessation programs?

No

Yes

4405

52.1

47.9

6077

Do not agree

Agree

2839

66.3

33.7

445

4311

5061

4.4

44.3

51.3

3131

47.3

52.7

25.8

1.00

Yes

3687

$21.6 \quad 1.00$
$24.8 \quad 1.20(1.07-1.35)^{*}$

$28.8 \quad 1.00$

$22.20 .71(0.57-0.88)^{* *}$

$22.3 \quad 1.00$

$22.30 .72(0.58-0.89)^{* *}$

${ }^{*} \mathrm{p}<0.05,{ }^{* *} \mathrm{p}<0.01$. 
public, give advice to their patients to stop smoking and whether they thought that such advice would be effective in helping patients quit (Table 1). In addition, five questions were also asked about the nature of their curriculum and their subsequent cessation interventions with respect to family members. The influence of the curriculum was assessed by asking about receipt of knowledge about the dangers of smoking and knowledge of the harmful health effects of light cigarettes. Respondents' behaviour related to tobacco was assessed with questions on whether they cared about SHS exposure and advised family members to stop smoking.

\section{Data analysis}

All data were entered into a database using Microsoft Excel. The data were then imported into SAS (9.3 version) for statistical analyses. Descriptive statistics were calculated to determine the prevalence of susceptibility to smoking. A logistic model was used to assess associations between the dependent and independent variables. Both unadjusted and adjusted methods were considered in the data analyses. The unadjusted method used only the key factors of interest as independent variables in the analyses, while the adjusted method added all of the possible confounders listed in Table 1 as covariates in the logistic models. We used binary logistic regression estimated with the maximum likelihood function. We present the final model with all covariates regressed on the dependent variable because we were cautious that step-wise inclusion (or its reverse) may be suspicious of p-hacking and the arbitrary discard of undesirable variables, which has elicited much controversy in current studies ${ }^{26}$. We also added OR and $95 \%$ CI in the statistic analysis section.

SAS survey logistic procedures were applied in the above analyses, using the university as the clustering unit, in order to account for a within-clustering correlation, attributable to the complex sample for unadjusted analysis. Series models were built for each primary predictor, with adjustment for the influence of potentially confounding sociodemographic characteristics in multiple variables logistic regression.

All analyses were weighted. Weights included: 1) sampling weights, as the inverse of the probability of selection, calculated at university; and 2) poststratification weights, calculated in relation to sex, based on estimated distributions of this characteristic from a national survey ${ }^{27}$. The final overall weights were computed as the product of the above two weights.

\section{RESULTS}

Valid questionnaires were completed by $97.6 \%$ of the potential students, resulting in a sample of 11954 students from 50 different universities. Subsequent analysis focused on 8916 non-smokers among medical students. Eleven percent of the resulting sample was less than 20 years of age, $19 \%, 22 \%$, and $25 \%$ were either 20, 21 and 22 years old, with the remainder of participants being more than 23 years old. Of the study sample, $31 \%$ were male, and $69 \%$ were female. In total, $95 \%$ of the participants were Han Chinese (Table 1).

The prevalence of susceptibility to smoking was $23.0 \%$ (95\% CI: 20.4-25.8\%). The unadjusted logistic analysis showed: those who were older, male, and whose fathers' occupations were workers, farmers, and in business were more likely to be susceptible to smoking. Exposure to SHS in living and public places, cigarette advertisement, and promotional activities on campus were positively associated with susceptibility to smoking. All attitudes toward health professionals involved in tobacco control were negatively associated with susceptibility to smoking. For example, students who thought that health professionals should serve as role models or obtain specific training in cessation techniques were much less likely to be susceptible to smoking, the respective ORs were 0.55 (95\% CI: $0.45-0.57)$ and 0.45 (95\% CI: 0.37-0.55). For the curriculum and behavioural variables, all except 'nicotine replacement therapies' were associated with susceptibility to smoking (Table 1).

Multilevel logistic regression confirmed that exposure to SHS in domestic and public places and the level of cigarette advertisements/promotional activities on campus were positively associated with susceptibility to smoking. All variables related to attitudes, except 'advising patients who use other tobacco products', were associated with susceptibility to smoking. Those who received information about the dangers of smoking, and did not agree that light cigarettes are less harmful to health were less susceptible to smoking. Caring about the effects of SHS and advising family members to stop smoking were negatively associated with susceptibility to smoking (Table 2 ). 


\section{Table 2. Results of multiple logistic regression}

\begin{tabular}{|c|c|c|c|}
\hline Group & $\mathbf{N}$ & $\begin{array}{c}\text { Prevalence } \\
(\%)\end{array}$ & $\begin{array}{l}\text { Adjusted OR } \\
\left(95^{\circ} \% \text { CI }\right)\end{array}$ \\
\hline \multicolumn{4}{|c|}{ Exposure to SHS } \\
\hline \multicolumn{4}{|c|}{ Exposure in domestic places in past week } \\
\hline No & 7338 & 12.6 & 1.00 \\
\hline Yes & 1578 & 26.4 & $1.63(1.20-2.20)^{* *}$ \\
\hline \multicolumn{4}{|c|}{ Exposure in public places in past week } \\
\hline No & 4805 & 14.0 & 1.00 \\
\hline Yes & 4111 & 16.0 & $1.78(1.08-2.93)^{*}$ \\
\hline
\end{tabular}

Cigarette advertisement and promotion

Did you see cigarette promotional activities on campus in past 6 months?

$\begin{array}{lrrr}\text { No } & 9212 & 22.3 & 1.00 \\ \text { Yes } & 461 & 37.1 & 1.90(1.30-2.78)^{* *} \\ \text { Did you see cigarette advertisement on campus in past 6 months? } & & & \\ \text { No } & 9104 & 22.0 & 1.00 \\ \text { Yes } & 570 & 38.1 & 1.91(1.33-2.75)^{* *}\end{array}$

Attitude toward health professions (HPs) tobacco control

Should HPs obtain specific training on cessation techniques?

No

$\begin{array}{lll}237 & 38.4 & 1.00\end{array}$

Yes

$9080 \quad 21.8 \quad 0.52(0.42-0.65)^{*}$

Should HPs serve as role models for their patients and the public?

No

$819 \quad 33.8 \quad 1.00$

Yes

$8998 \quad 22.0 \quad 0.61(0.48-0.80)^{* *}$

Should HPs routinely advise patients to stop smoking?

No

$\begin{array}{lll}442 & 38.9 & 1.00\end{array}$

Yes

9375

22.4

$0.49(0.35-0.70)^{* *}$

Do HP have role in providing advice or information about smoking cessation to patients?

No

$1257 \quad 28.8 \quad 1.00$

Yes

8560

22.2

$0.73(0.57-0.94)^{*}$

Are patient chances of quitting smoking increased with advice from HP?

No

$1213 \quad 22.3 \quad 1.00$

Yes

8604

22.3

$0.78(0.63-0.97)^{*}$

\section{Curriculum and behaviors}

In school training, did you receive information about the dangers of smoking?

No

Yes

Light cigarettes are less harmful to health

Do not agree

Agree

Do you care about others smoking around you?

No

Care

Very

Did you advise your family members to stop smoking?

No

Yes

$\begin{array}{rrl}1802 & 27.5 & 1.00 \\ 8015 & 22.1 & 0.75(0.60-0.95)^{*} \\ & & \\ 6077 & 13.1 & 1.00 \\ 2839 & 18.5 & 1.27(1.07-1.64)^{* *} \\ & & \\ 445 & 47.4 & 1.00 \\ 4311 & 26.5 & 0.68(0.56-0.84)^{* *} \\ 5061 & 18.0 & 0.33(0.23-0.49)^{* *} \\ & & \\ 3131 & 25.8 & 1.00 \\ 3687 & 19.5 & 0.81(0.68-0.97)^{*}\end{array}$

${ }^{*} p<0.05,{ }^{* *} p<0.01$. 


\section{DISCUSSION}

To our knowledge, this is the first study examining susceptibility to smoking and determinants among medical students in China and elsewhere in the world. In this study, we estimated the susceptibility to smoking among never-smoking medical students and also identified associated factors.

The first aim of the study addressed the question of quantifying the prevalence of susceptibility to smoking among medical students. This study found that the prevalence of susceptibility to smoking among never-smoking medical students was $23.0 \%$. This prevalence was higher than the prevalence (12.5\%) in adolescents (Global Youth Tobacco Survey) ${ }^{2,28}$. This high prevalence of susceptibility may in part explain the high smoking prevalence observed among practising physicians in China. Though the higher smoking prevalence among physicians in China may be associated with social factors ${ }^{16}$, their attitudes and practices of smoking gradually form and become inseparable from their early experiences ${ }^{22}$. This high prevalence of susceptibility is problematic, especially if susceptibility leads to subsequent initiation and the continuation of a relatively high rate of smoking among Chinese medical students. We intend to study how future medical professionals are susceptible to smoking; we believe this association can be built because the pipeline from medical students to medical professionals is very saturated and very few medical students work outside the healthcare industry including public hospitals, private clinics, and other healthcare units ${ }^{24}$. While not all medical students eventually settle into employment as physicians, all physicians were previous medical students. Susceptibility to smoking among medical students ultimately shapes the initial experience about the normativity of smoking for the vast majority of healthcare workers. Many studies have shown that susceptible adolescents were two to three times more likely to experiment with cigarettes later on than non-susceptible adolescents ${ }^{2,5,6}$. This should also be true for medical students. Thus, it is important to implement early intervention efforts and prevent never-smoking medical students from initiating smoking and transitioning to regular smokers.

Our finding that older males in particular had a higher risk of susceptibility to smoking is consistent with normative patterns in China where smoking is an accepted adult practice predominantly among males compared to females ${ }^{29}$. Given that being susceptible to smoking is an important risk factor for future smoking behaviour, targeted smoking prevention efforts during medical training are warranted. Based on our study results, targeted efforts directed toward older male students should be a priority.

The second important aim of the study was to examine the role of environmental factors in susceptibility to smoking. The findings showed that exposure to SHS at home and in public places was significantly associated with increased susceptibility to smoking among never-smoking individuals. This finding is consistent with studies from other populations where smoking in public and private spaces helps reinforce pro-smoking norms ${ }^{2,3}$. Not surprisingly, we also found that those who care about SHS were less likely to be susceptible to smoking. Consistent with this result, Mayhew et al. ${ }^{30}$ reported that experiencing physical and/or unpleasant reactions to SHS exposure predicted lower risk for smoking susceptibility ${ }^{30}$. Exposure to SHS causes many serious diseases. However, millions of non-smokers remain exposed to SHS in their homes, workplaces, public places, and vehicles. The World Health Organization (WHO) has estimated that in 2004, about one-third of adults and $40 \%$ of children worldwide were exposed to $\mathrm{SHS}^{31}$.

Smoke-free policies are the most effective way to reduce exposure to tobacco smoke among the public ${ }^{31}$. Given that most medical students live on campus, study findings support the need to create smokefree campuses, to protect young adult never-smokers from exposure to SHS. In medical universities, a smoke-free campus policy would also promote a healthy campus environment for students, faculty, staff, and visitors, support and encourage cessation attempts among smokers trying to quit, and indicate strong support for tobacco control among university leaders ${ }^{22}$. In addition, a smoke-free campus is a good way to strengthen attitudes toward protecting others from SHS and support medical student involvement in promoting tobacco control. Medical students could be encouraged to advocate a smoke-free campus policy and participate in related activities. The study findings also support the need to implement comprehensive tobacco bans along with stronger regulations of tobacco company advertising practices. The FCTC 
requires that each party to the Convention 'undertake a comprehensive ban, and restrict tobacco advertising, promotion, and sponsorship on radio, television, print media, and also, as appropriate, other media such as the Internet ${ }^{\prime 17}$. Several studies have documented that complete bans on tobacco advertising and promotion can protect youth from initiating smoking and adults from continuing to smoke ${ }^{32,33}$. Many studies have also found clear associations between cigarette advertisement/promotion and susceptibility to smoking among adolescents ${ }^{34-36}$. This study provided evidence for this relationship. With knowledge of the health risks of smoking and tobacco control measures, medical students could be involved in lobbying against cigarette advertisement/promotion, and restricting the sale of tobacco products on campuses as part of nation-wide efforts to introduce policies to ban tobacco advertising/promotion activities in public places in China.

For our third aim, this study tested students' tobacco control attitudes, curriculum influences, and other behaviours associated with susceptibility to smoking. We found that the positive attitudes toward health professionals' role in tobacco control included in this study were commonly associated with low susceptibility to smoking. Susceptible, never smokers held stronger negative opinions about health professionals' role in tobacco control than never smokers who were not susceptible to smoking. Previous research has demonstrated that anti-smoking norms and attitudes are related to lower smoking prevalence ${ }^{37,38}$. Furthermore, receipt of information about the dangers of smoking was negatively associated with susceptibility to smoking while thinking that 'light cigarettes are less harmful to health' was positively associated with susceptibility to smoking. Together, these study findings underscore the importance of strengthening medical education related to the role of physicians in tobacco control as well as knowledge and skills related to supporting cessation. It is likely important to include this circular content early in medical programs before students progress to becoming current smokers. Such training is important because it not only influences students' susceptibility to smoking but also may enhance awareness of physician roles in tobacco control, as well as attitudes and behaviours regarding smoking cessation.
Medical professions have the potential to play a critical role in tobacco control in relation to improving services, advocating policies and serving as role models for social change. Currently, there are approximately 190 universities offering programs in public health, nursing, and clinic medicine in China. Nearly 100000 students graduate annually from these faculties, with a significant number being employed by medical institutes ${ }^{38}$.

The tobacco epidemic is a major public health threat in China. Although the Chinese National People's Congress ratified the Framework Convention on Tobacco Control (FCTC) in 2005, implementation of the FCTC recommended activities is progressing very slowly. This slow progress is related to the lack of skilled personnel who can act as advocators to promote anti-tobacco activities. This situation may be related to tobacco control training in medical schools. However, it is gratifying to see that this situation is beginning to change. As a result of this survey, 'building advocacy capacity' BI (the Bloomberg Global Initiative Project) projects have involved medical students in 98 universities in China. For example, a project focused on tobacco dependence treatment is in its last year. In this project, a general clinic smoking cessation program was development, and implemented in 10 hospitals, and embedded in the medical curriculum in 50 Universities. In these projects focusing on enhancing tobacco control and smoking cessation capacity training, smoke-free campuses are being implemented. These projects have effectively increased the capacity of the medical community in tobacco control advocacy ${ }^{38,39}$, and contributed to China's tobacco control.

\section{Limitations}

The study has strengths and limitations. It is the first study to estimate and identify factors associated with smoking susceptibility among never-smoking young adults on a national scale. The cross-sectional study design is an important limitation of our study. Therefore, a causal link between study variables and smoking susceptibility cannot be established. However, we employed a large sample, and our findings met several criteria for inferring causality, including the strength of some associations, their consistency, and plausibility of effect. Future studies need to compile longitudinal surveillance data to 
examine smoking susceptibility and initiation. A second study limitation is bias in our study, as some possible potential confounding factors were not controlled.

\section{CONCLUSIONS}

This study provides new information about susceptibility to smoking and its determinants among medical students in China. This may help to partly understand the high smoking prevalence among physicians in China. These findings underscore the importance of conducting tobacco control training and establishing smoke-free campuses for reducing susceptibility to smoking among medical students.

\section{REFERENCES}

1. Ertas N. Factors associated with stages of cigarette smoking among Turkish youth. Eur J Public Health. 2007;17(2):155-161. doi:10.1093/eurpub/ck1095

2. Veeranki SP, Mamudu HM, Anderson JL, Zheng Set. Worldwide never-smoking youth susceptibility to smoking. J Adolesc Health. 2014;54(2):144-150. doi:10.1016/j.jadohealth.2013.07.036

3. Pierce JP, Choi WS, Gilpin EA, Farkas AJ, Merritt RK. Validation of susceptibility as a predictor of which adolescents take up smoking in the United States. Health Psychol. 1996;15(5):355-361. doi:10.1037//0278-6133.15.5.355

4. Valdés-Salgado Raydel, Myriam RSL, Eduardo LPHernández-Avila Mauricio. Susceptibility to Smoking among Adolescents and Its Implications for Mexico's Tobacco Control Programs. Analysis of the Global Youth Tobacco Survey 2003-2004 and 2006-2007. Int J Environ Res Public Health. 2009;6(3):1254-1267. doi:10.3390/ijerph6031254

5. Unger JB, Johnson CA, Stoddard JL, Nezami E, Chih-Ping C. Identification of adolescents at risk for smoking initiation: validation of a measure of susceptibility. Addict Behav. 1997;22(1):81-91. doi:10.1016/0306-4603(95)00107-7

6. Prokhorov AV, de Moor CA, Hudmon KS, Hu S, Kelder SH, Gritz ER. Predicting initiation of smoking in adolescents: evidence for integrating the stages of change and susceptibility to smoking constructs. Addict Behav. 2002;27(5):697-712. doi:10.1016/s0306-4603(01)00203-9

7. Gritz ER, Prokhorov AV, Hudmon KS, Rosenblum C, Chang CC, Chamberlain RM, et al. Predictors of susceptibility to smoking and ever smoking: A longitudinal study in a triethnic sample of adolescents. Nicotine Tob Res. 2003;5(4):493-506. doi:10.1080/1462220031000118568

8. Altman DG, Levine DW, Coeytaux R, Slade J, Jaffe R. Tobacco promotion and susceptibility to tobacco use among adolescents aged 12 through 17 years in a nationally representative sample. Am J Public Health. 1996;86(11):1590-1593. doi:10.2105/ajph.86.11.1590

9. Feighery E, Borzekowski DL, Schooler C, Flora J. Seeing, wanting, owning: The relationship between receptivity to tobacco marketing and smoking susceptibility in young people. Tob Control. 1998;7(2):123-128. doi:10.1136/tc.7.2.123

10. Flay BR, Koepke D, Thomson SJ, Santi S, Best JA, Brown KS. Six-year follow-up of the first Waterloo school smoking prevention trial. Am J Public Health .1989;79(10):1371-1376. doi:10.2105/ajph.79.10.1371

11. Huang C, Koplan JP, Liu J, Li C, Silvaggio J. Smoking susceptibility and its predictors among adolescents in China: Evidence from Ningbo City. J Addict Res Ther. 2012;S8:004. doi:10.4172/2155-6105.s8-004

12. Okoli CTC, Rayens MK, Wiggins AT, Ickes MJ, Butler KM, Hahn EJ. Secondhand tobacco smoke exposure and susceptibility to smoking, perceived addiction, and psychobehavioral symptoms among college students. J Am Coll Health. 2016;64(2):96-103. doi:10.1080/07448481.2015.1074240

13. Lipkus IM, Reboussin BA, Wolfson M, Sutfin EL. Assessing and predicting susceptibility to waterpipe tobacco use among college students. Nicotine Tob Res. 2015;17(9):1120-1125. doi:10.1093/ntr/ntu336

14. Yang T. Health research: social behavioural theory and methods. Beijing, China: People's Medical Publishing House; 2018:72-132.

15. Barnett R, Moon G, Pearce J, Twigg L. Smoking Geographies: Space, Place and Tobacco. London, UK: Wiley-Blackwell;2017.

16. Aryal UR, Petzold M, Bondjers G, Krettek A. Correlates of smoking susceptibility among adolescents in a periurban area of Nepal: a population-based cross-sectional study in the Jhaukhel-Duwakot Health Demographic Surveillance Site. Glob Health Action. 2014;7(1):24488. doi:10.3402/gha.v7.24488

17. Jiang Y, Ong MK, Tong EK, Yang Y, Nan Y, Gan Q, Hu TW . Chinese physicians and their smoking knowledge, attitudes, and practices. Am J Prev Med. 2007;33(1):1522. doi: $10.1016 /$ j.amepre.2007.02.037

18. World Health Organization. WHO Report on the Global Tobacco Epidemic, 2013: Enforcing bans on tobacco advertising, promotion and sponsorship. Geneva, Switzerland: World Health Organization; 2013. https://apps.who.int/iris/bitstream/ handle/10665/85380/9789241505871_eng. pdf;jsessionid=CF 84FEF68C 1 AE 19B 362011 D7816CB7B0?sequence=1. Accessed January 14, 2019.

19. Tong EK, Strouse R, Hall J, Kovac M, Schroeder S. National survey of US health professionals' smoking prevalence, cessation practices, and beliefs. Nicotine Tob Res. 2010;12(7):724-733. doi:10.1093/ntr/ntq071

20. World Health Organization. The role of health 
professionals in tobacco control. Geneva, Switzerland: World Health Organization; 2005.

21. La Torre G, Kirch W, Bes-Rastrollo M, Ramos RM, Czaplicki M, Gualano MR, et al. Tobacco use among medical students in Europe: results of a multicentre study using the Global Health Professions Student Survey. Public Health. 2012;126(2):159-164. doi:10.1016/j.puhe.2011.10.009

22. Nelson DE, Giovino GA, Emont SL, Brackbill R, Cameron LL, Peddicord J, Mowery PD. Trends in cigarette smoking among US physicians and nurses. JAMA. 1994;271(16):12731275. doi:10.1001/jama.1994.03510400059032

23. Yang T, Yu L, Bottorff JL, Wu D, Jiang S, Peng S, Young KJ. Global Health Professions Student Survey (GHPSS) in Tobacco Control in China. Am J Health Behav. 2015;39(5):732-741. doi:10.5993/ajhb.39.5.14

24. New Jincin. The research on employment quality of college graduates. Beijing, China: Modern Press; 2016.

25. Wang JP. Research on the current situation and countermeasure of medical students' employment in Anhui Province. Hedei, Switzerland: Anhui Medical University; 2012.

26. Wang Y. College entrance examination inquires, 2016. http://www.gaokao.com/baokao/lqfsx/ybfsx/. Accessed April 20, 2019.

27. Rubin M. An evaluation of four solutions to the forking paths problem: adjusted alpha, preregistration, sensitivity analyses, and abandoning the Neyman-Pearson approach. Rev Gen Psychol. 2017;21(4):321-329. doi:10.1037/gpr0000135

28. National Ministry of Education. Annual report on university graduates' employment in 2015. http://news. sohu.com/20131107/n389748218.shtml. Accessed January 14, 2019.

29. Guindon GE, Georgiades K, Boyle MH. Susceptibility to smoking among South East Asian youth: a multilevel analysis. Tob Control. 2008;17(3):190-197. doi:10.1136/tc.2007.022285

30. Unger JB, Yan L, Chen X, Jiang X, Azen S, Qian $\mathrm{G}$, et al. Adolescent smoking in Wuhan, China: baseline data from the Wuhan smoking prevention trial. Am J Prev Med. 2001;21(3):162-169. doi:10.1016/s0749-3797(01)00346-4

31. Mayhew KP, Flay BR, Mott JA. Stages in the development of adolescent smoking. Drug Alcohol Depend. 2000;59(Suppl 1):61-81. doi:10.1016/s0376-8716(99)00165-9

32. World Health Organization. Second-hand smoke: assessing the burden of disease at national and local levels. Geneva, Switzerland: World Health Organization; 2008.

33. Biener L, Siegel M. The role of tobacco advertising and promotion in smoking initiation. In: Smoking and Tobacco Control Monograph No 14. U.S. Department of Health and Human Services, Public Health Service,
National Institutes of Health, National Cancer Institute; 2006:201-212.

34. Nelson JP. Gigarette demand, structural change, and advertising bans: international evidence, 19701995. Contributions in Economic Analysis \& Policy. 2003;2(1):10-15. doi:10.2202/1538-0645.1111

35. Sargent JD, Dalton M, Beach M, Bernhardt A, Heatherton T, Stevens M. Effect of cigarette promotions on smoking uptake among adolescents. Prev Med. 2000;30(4):320327. doi:10.1006/pmed.1999.0629

36. Lovato G, Linn G, Stead L. Impact of tobacco advertising and promotion on increasing adolescent smoking behaviours. Cochrane Database Syst Rev. 2011;10:CD003439. doi:10.1002/14651858.cd003439

37. Castrucci BC, Gerlach KK, Kaufman NJ, Orleans CT. The association among adolescents' tobacco use, their beliefs and attitudes, and friends' and parents' opinions of smoking. Matern Child Health J. 2002;6(3):159-167.

38. Yang T, Peng S, Yu L, Jiang S, Stroub WB, Cottrell RR. Rockett IR. Chinese smokers' behavioral response toward cigarette price: individual and regional correlates. Tob Induc Dis. 2016;14(April). doi:10.1186/s12971-016-0078-7

39. Yang T, Abdullah AS, Rockett IRH, Li M, Zhou Y, Ma J, et al. Assessment of tobacco control advocacy behavioral capacity among students at schools of public health in China. Tob Control. 2011;20(1):20-25. doi:10.1136/tc.2010.036590

\section{ACKNOWLEDGEMENTS}

We thank local teams from the 'Building advocacy capacity for tobacco control in medical universities in China' programme for organizing the data collection.

\section{CONFLICTS OF INTEREST}

The authors have completed and submitted the ICMJE Form for Disclosure of Potential Conflicts of Interest and none was reported.

\section{FUNDING}

This study was partly funded by the National Nature Science Foundation of China (71490733) and Global Bridges/IGLC, 2014SC1 (13498319).

\section{AUTHORS' CONTRIBUTIONS}

TY and SJ conceived the study design, conceptualized the ideas, and supervised the data management and analyses. SP, LY and DW conducted the data collection. TY wrote the preliminary draft, while BJ and $B R$ revised and edited the manuscript. All authors reviewed earlier drafts and approved the final version.

\section{PROVENANCE AND PEER REVIEW}

Not commissioned; externally peer reviewed. 